\title{
Medical audit and mental health care
}

\author{
Gyles R. Glover, Lecturer in Community Medicine, Charing Cross and Westminster \\ Medical School, 17 Horseferry Road, London SWIP 2AR
}

The recent prominence of medical audit in psychiatry is due in large measure to the place given to the subject in the government's White Paper Working for Patients (DoH, 1989a). However, medical audit existed before the White Paper and covers a broader scope than the White Paper proposes. Thus in considering the introduction of audit into the mental health services it is important not to allow the White Paper to narrow the field of view.

\section{The White Paper and the British context}

Working for Patients proposes a health care system based on managed competition between care providers with treatments priced in advance. The White Paper recognises that in such a system medical audit has two essential roles. Firstly, provider organisations have a financial incentive to minimise the cost of treatments and thus medical audit is needed to ensure that they do not cut corners too far and produce sub-standard care. Secondly, managers within the organisations are inclined to seek audit mechanisms (of the 'utilisation review' type) to ensure that within the bounds of reasonable practice, clinicians work parsimoniously.

But medical audit in the UK has a longer and more noble history than this. The self-regulation of the medical profession received wide and detailed consideration, both by the profession itself and by the public and in Parliament through most of the 1970s (DHSS, 1975; Alment, 1976; Anon, 1976). Medical audit was a recurring theme in this debate. Many felt it could be construed as a component of what the authors of the Merrison Report (DHSS, 1975) called the 'contract between the public and the profession'. The privilege of self-regulation carried the duty of self-regulation.

The natural bodies to promote and co-ordinate the task have been the Royal Colleges. The Obstetricians and Gynaecologists (DoH, 1989b) were the pioneers, a reflection of the highly quantifiable nature of the work they oversee. More recently most others have followed and concluded, independently of Working for Patients, that hospitals without adequately developed medical audit programmes should not be accredited for higher specialist training. The goals of medical audit in this context could roughly be summarised as ensuring that:

(a) practising doctors maintain a high degree of competence in their spheres of medicine

(b) high standards of professional conduct are maintained (an area relatively neglected in audit literature)

(c) the facilities within which care is delivered are adequate for the requirements of the job

(d) the greatest possible benefit is obtained from scarce resources.

By contrast, the goals for audit in the White Paper are the inevitably narrower preoccupations of a funding body:

An effective programme of audit will help to provide the necessary reassurance to doctors, patients and managers that the best quality of service is being achieved within the resources available. (DoH, 1989a, Working Paper 6, para 1.1)

It is important that the profession should recognise that the audit called for in the White Paper is thus about the 'contract' between the profession and the Department of Health, not the one between the profession and the public. What will suffice for the former, essentially surveillance of the components of efficiency, is rather less than is required for the latter, which needs to examine not only wider questions within a district, but also analyses between districts and ideally comparisons between the public and the private sectors.

\section{Medical audit in psychiatry}

In view of the complex and publicly contentious ethical issues confronted by psychiatrists, it is surprising that they have been relatively late in entering the field of audit. Perhaps the explanation lies in the formidable technical difficulties posed. Measuring outcomes of treatment, deciding whether changes result from treatment or from other events in the patient's life, sometimes even defining the treatment given to patients' all present formidable problems. Multidisciplinary working complicates the process since many more individuals are likely to wish to be involved than in more traditional areas of medicine, often with differing theoretical perspectives. 
However, there are obvious starting points. The methods of mutual random case review, statistical analysis of the quantifiable aspects of the use of services by patients, and 'disaster audit' are clearly of relevance. Areas needing particular attention are the propriety of the use of compulsory detention and treatment and the care of the demented, the mentally handicapped and the chronically mentally ill (groups less able to look after themselves).

\section{Where will it lead?}

Having distinguished between a narrow, efficiency oriented view of audit and a broader view of upholding professional standards, it can be seen that the types of conclusion that may be reached from these two approaches differ. Audits of efficiency can, at best, improve efficiency (at worst they can lead to cost cutting at the expense of service levels). Audits of standards, preferably with a broad perspective, may improve standards. Surely this should be the primary aim of professional audit. Evidence from the literature suggests that this more positive outcome is indeed possible. Two recent accounts are worth considering in this respect.

Gumpert (1988) described how a key result of audit in the surgical services in Brighton was the appointment of a department manager, selected by and answerable to the consultants, but with wide discretion and with the remit simply to improve the general organisation of the service. This was a response to the realisation that the service was administratively under-resourced to the extent that doctor's and nurse's time could not be efficiently used.

It has already been noted that obstetric services developed audit methods earlier and more thoroughly than other UK clinical disciplines. Mathews (1989), in a recent commentary on the Government's audit proposals, noted that despite this, the specialty had not been mentioned in Working Paper 6. He suggested this was because "Medical audit as we know it in obstetrics is not designed to curtail expenditure, all the pressures that arise from it are in the other direction ... (it has become) a stick with which to whack more money out of the government."

But these positive outcomes are attainable only if clinicians, auditing their work, address the right questions. If they do, the evidence it presents combined with the fact of scrupulous self-regulation can offer an armoury of information and a moral highground in the fight for resources. If they remain passive and allow managers and their assistants to set up efficiency based audit systems, that opportunity will be lost.

\section{Acknowledgement}

I am grateful to Sir Anthony Alment and Professor K. Rawnsley for their helpful comments about the enquiries into the regulation of the medical profession in the 1970s.

\section{References}

Alment, E. A. J. (Chairman) (1976) Competence to Practice: The Report of a Committee of Enquiry set up for the Medical Profession in the United Kingdom. Available from the publications department of the Royal College of Obstetricians and Gynaecologists, London.

ANONYMOUs (1976) Separating the sheep from the goats. British Medical Journal, 2, 1218.

DHSS (1975) Report of the Committee of Enquiry into the Regulation of the Medical Profession (the Merrison report). London: HMSO.

DoH (1989a) Working for Patients. Cm 555 and supplementary Working Paper No 6. London: HMSO.

DoH (1989b) Report on Confidential Enquiries into Maternal Deaths in England and Wales 1982-1984. Report on Health and Social Subjects Series, No 34. London: HMSO. (See chap 19 for an overview of the confidential enquiries since 1952.)

GUMPERT, J. R. (1988) Why on earth do surgeons need quality assurance? Annals of the Royal College of Surgeons of England, 70, 85-92.

MATHEWS, D. D. (1989) Called to account: an obstetrician. The Lancet, i, 661-662. 